\title{
INVESTIGATION ON STRENGTHENING OF REINFORCED CONCRETE BEAMS WITH GFRP COMPOSITES MODIFIED BY SILANE AGENT
}

\author{
Sara Rafiee \\ MSc. Student, Faculty of Science and Technologies, \\ Tarbiat Modares University, Tehran, Iran \\ Sadegh Dardaei* \\ Assistant Professor, Faculty of Science and Technologies, \\ Tarbiat Modares University, Tehran, Iran \\ Hamed Bagheri \\ Assistant Professor, Faculty of Science and Technologies, \\ Tarbiat Modares University, Tehran, Iran \\ *Corresponding Author
}

\begin{abstract}
Concrete structures are known as reliable structures, but some construction errors and construction negligence can lead to defects in these structures. The defects can be due to poor design practices, poor quality control, or poor structural design and detailing. In recent years, various strengthening methods, including the use of polymer composites, have gained much attention to resolve the defects, especially for the flexural elements. Glass fiber-reinforced polymers (GFRPs), as a common type of composite materials, comprise two components, namely the matrix and fibers. This paper investigates the effects of the silane surface modifier on the resistance of GFRP and the capacity of the reinforced concrete beams. For this purpose, the silanemodifying agent of 3-aminopropyltriethoxysilane (APTES) with an adequate weight percentage is used as a modifier, and the composite samples are fabricated and tested with and without the surface modifier. The results of the experimental studies are used in numerical studies. The capacity of beams strengthened with the GFRP composites (including composites with modifier and composite without a modifier) is determined using finite element analysis and compared with the capacity of a beam without strengthening. Numerical analysis results indicate that the use of GFRP composite without the silane surface modifier increases the capacity of the beam by approximately 15\%. On the other hand, the use of GFRP composite with silane surface modifier increases the capacity of the selected beam by about $28 \%$.
\end{abstract}

Keywords: Numerical analysis; (GFRP) composites; Silane surface modifier; Reinforced concrete beams 
Cite this Article: Sara Rafiee, Sadegh Dardaei and Hamed Bagheri, Investigation on Strengthening of Reinforced Concrete Beams with GFRP Composites Modified by Silane Agent, International Journal of Civil Engineering and Technology (IJCIET), 12(2), 2021, pp. 1-10. https://iaeme.com/Home/issue/IJCIET?Volume=12\&Issue=2

\section{INTRODUCTION}

The study of the damages caused by past earthquakes indicates that a high percentage of constructed reinforced concrete buildings are either not earthquake-resistant or have insufficient resistance. This inadequacy is because many existing reinforced concrete structures are often designed according to outdated seismic codes. Most of these structures fail to meet the requirements of the latest seismic regulations. Implementation shortcomings have rendered buildings more vulnerable. Given that many of these structures are crucial in various respects substituting them with new structures is not feasible from both the economic and practical standpoint. Meanwhile, repairing and strengthening the same structures is deemed necessary and cost-effective. Hence, the need to strengthen these buildings, particularly for lateral force using reliable, easy, quick, and cost-effective reinforcement methods, are among the top agendas in this regard. For most buildings, structural strengthening is often far more economical than rebuilding them. As a result, many researchers have come to consider the matter of retrofitting structures on these grounds. Structural strengthening is mostly performed to increase strength and improve the ductility of the existing structural elements. So, there is an urge for flexural strengthening of concrete beams considering their frequent uses. Overall, flexural strengthening of concrete beams by different methods such as strengthening with steel sheets, concrete coating, or polymer fibers has also gained many researchers' attention. These methods serve to increase flexural (modulus of rupture) or shear strength, or both at the same time.

Externally bonded fiber-reinforced polymer (FRP) sheets are now recognized as an effective technique for strengthening reinforced concrete (RC) structures. Compared to the traditional materials, FRP composites have high strength and stiffness, lighter weight, lesser thickness, corrosion, and chemical resistance. The strengthened structures with FRP composites display behavior changes in ductility, strength, and failure mode.

The properties of FRP composite are derived from the properties of resins and fibers. So, if a material can be added to the composite as an additive to modify the mechanical parameters of FRP fibers and create stronger internal bonds in the composite, composites with more optimal properties can be achieved to strengthen structural elements. It can also be economically viable to achieve the desired design strength by using modifiers with lower amounts of fibers and resins.

Previous studies on the strengthening of concrete beams with FRP composites reveal an increase in the strength and a decrease in the flexibility of the beams compared to the prestrengthened state. Rahaei et al. (2006) [1] conducted static and cyclic loading on concrete beams reinforced with FRP composite. The results showed an increase in the flexural capacity and stiffness of the beams after the retrofit. Hoshyar Imani et al. (2009) [2] studied the bearing capacity, extent, and type of cracks in concrete beams reinforced with FRP sheets. According to their results, strengthening with FRP composite increases the ultimate stiffness and strength of the flexural elements. Similarly, Rajan et al. (2018) examined and modified the mechanical properties of epoxy resin by silane surface modifier [3]. In another study, Memar et al. (2016) investigated the impact of adding trimethoxysilane silane agent on the properties of vinyl ester resin [4]. Furthermore, Kijiang Yu et al. (2013) studied the impact of 
surface modifiers on the mechanical properties of carbon-glass fiber core composites [5]. Dardaei et al. (2020) investigated the experimental modification of different resins using polyether ether ketone (PEEK) as an additive. After demonstrating the effectiveness of PEEK in improving GFRP composite's properties, they investigated the effect of modified resin properties on the general behavior of an RC beam [6].

Various methods are used to modify the properties of thermostatic resins, including the addition of nanoparticles (e.g., clay, silicon dioxide, and carbon nanotubes) and liquid additives like the active monomers (e.g., acrylate and silane compounds). Silane compounds with the organic-inorganic hybrid structure are employed as a coupling agent and adhesion promoter between the organic phase of the upper layer and the secondary organic or inorganic phase. In turn, this phase can be wooden, metal, or other polymer surfaces [7]. Silane modifier reagents are organic silicon compounds that are broadly used for binding organic materials to inorganic ones. These modifiers are employed to achieve a better interfacial adhesion in composites and other materials, mechanical strength, chemical resistance, hygroscopicity, and electrical properties. Generally speaking, a silane modifier agent modifies the surface of inorganic particles via two methods, namely physical adsorption and chemical bonding [7].

This study consists of two parts: experimental studies and numerical studies. In the experimental studies, the effect of using the (3-aminopropyl) triethoxysilane (APTES) as a surface modifier in GFRP composite fabrication is investigated. For this purpose, the composite samples are fabricated and tested with and without the surface modifier. The results of the experimental studies of the composites are used in numerical studies. The flexural capacity of beams strengthened with the GFRP composites (including composites with modifier and composite without a modifier) is determined using finite element analysis and compared with the capacity of a beam without strengthening as a control sample.

\section{EXPERIMENTAL STUDY}

\subsection{Materials}

LR-615 epoxy resin with the H-515 hardener (product of Iran Composite Company) was used as the base material in the present study. The unidirectional glass fiber reinforced polymeric composites with a density of 300 produced by "Iran Composite Company" was used as a fiber reinforcing agent in the fabrication process of composite samples. The silane modifying agent, 3-aminopropyltriethoxy silane (product of Safir Azma Company) with a weight ratio percentage of $1 \%$, was further applied to modify the fiber surfaces and improve the adhesion with resin. Tables 1 and 2 display the main properties of epoxy resin and glass fibers, respectively.

Table 1. The technical properties of the epoxy resin

\begin{tabular}{|l|l|}
\hline Percentage of hardener & $\% 15$ \\
\hline Gelation Time & $\mathbf{1 ~ h r}$ \\
\hline$T_{\mathrm{g}}$ & $\mathbf{8 0}{ }^{\circ} \mathrm{C}$ \\
\hline Density & $\mathbf{1 . 0}\left(\mathrm{gr} / \mathrm{cm}^{\mathbf{3}}\right)$ \\
\hline
\end{tabular}

Table 2 The technical properties of the glass fibers

\begin{tabular}{|l|l|}
\hline Density & $\mathbf{2 . 5 5}\left(\mathrm{gr} / \mathrm{cm}^{\mathbf{3}}\right)$ \\
\hline Primary Fiber direction & $\mathbf{0}^{\circ}($ Unidirectinal $)$ \\
\hline Fabric Thickness & $\mathbf{0 . 1 6} \mathbf{~ m m}$ \\
\hline Tensile strength & $\mathbf{2 2 0 0} \mathbf{M p a}$ \\
\hline Elongation & $\mathbf{\% 3}$ \\
\hline
\end{tabular}




\subsection{Fabrication of Samples}

Two different sample types are fabricated in this section: EPG0 and EPG1. The EPG0 samples are composite samples prepared with glass fibers and epoxy resin without a surface modifier. The EPG1 samples are composite samples prepared with glass fibers and epoxy resin with $1 \%$ silane surface modifier of 3-aminopropyltriethoxysilane (APTES).

Considering the type of used materials, the most convenient way for fabricating the sample is to impregnate the fibers with resin (manual layering). The samples used in this study are prepared according to ASTM-5638-1 [8] and ASTM-D3039 [9].

Unmodified EPG0 samples were prepared with epoxy resin according to the following procedure. First, the epoxy resin and its hardener with a weight ratio of 100 to 15 are compounded and then blended well until a homogeneity state is obtained. Next, the glass fibers are cut into $1.5 \mathrm{~cm} \times 25 \mathrm{~cm}$ pieces according to the proposed standard guidelines, and both sides are thoroughly impregnated with resin. According to the guideline, a $1.5-\mathrm{cm}$ tab was attached to both sides of the samples using the resin to prevent the samples from crushing at the grip chuck of the traction device. The trapped air bubbles were then excluded by applying pressure. Finally, the samples were set at room temperature for 24 hours to perform the final curing. The above procedure is further followed through to render modified EPG1 samples, except that the silane modifying agent with a weight ratio of $1 \%$ is added before blending the resin and hardener. The rest of the sample fabrication and curing steps are the same as those performed for preparing the EPG0 samples. The prepared samples are presented in figures 1 and 2.

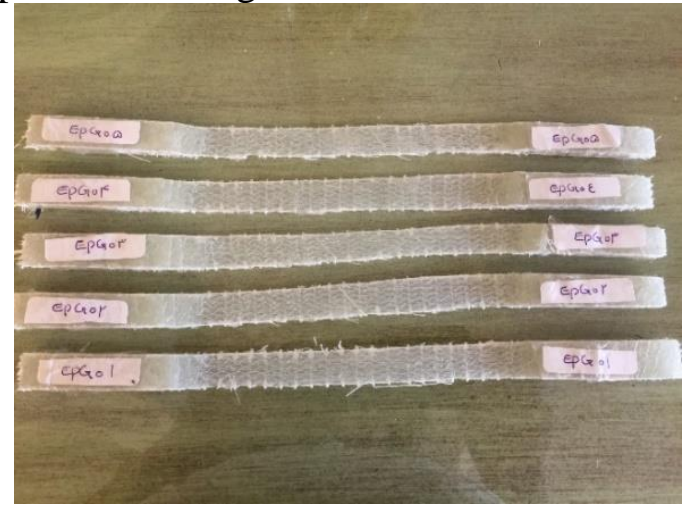

Figure 1 EPG0 samples prepared to undergo tensile testing

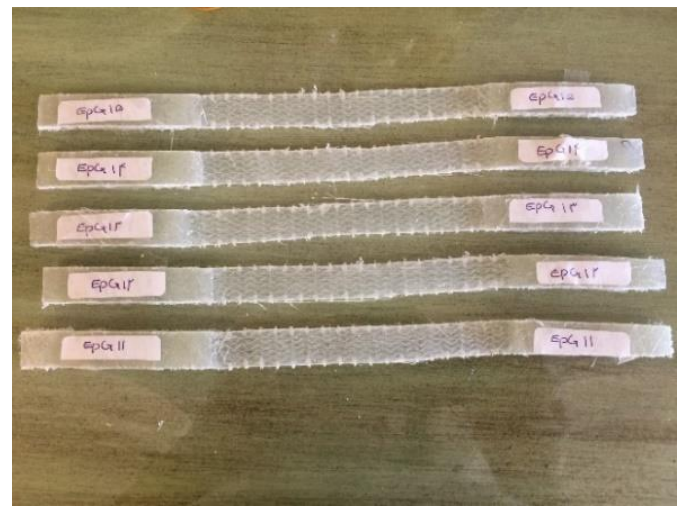

Figure 2 EPG1 samples prepared to undergo tensile testing

\subsection{Tensile Testing of Samples}

The tensile testing procedure is conducted following the ASTM-D3039 [9]. The tests were performed by a ball screw universal tensile testing machine. The testing results are presented in Table 3. As illustrated in Table 3, adding the silane agent caused a $60 \%$ and $36 \%$ increase in tensile strength and tensile modulus of EPG1 samples, respectively. The samples after the tensile test are presented in figures 3 and 4 .

Table 3 Tensile testing results for the prepared samples

\begin{tabular}{|c|c|c|c|c|c|c|c|}
\hline \multirow{2}{*}{ No } & \multirow{2}{*}{$\begin{array}{c}\text { Sample } \\
\text { code }\end{array}$} & \multicolumn{3}{|c|}{ Dimension of samples } & \multirow{2}{*}{$\begin{array}{c}\begin{array}{c}\text { Ultimate } \\
\text { tensile } \\
\text { strength }\end{array} \\
(\mathrm{MPa}) \\
\end{array}$} & \multirow{2}{*}{$\begin{array}{c}\begin{array}{c}\text { ultimate } \\
\text { strain }\end{array} \\
\mathbf{e}\end{array}$} & \multirow{2}{*}{$\begin{array}{c}\text { tensile } \\
\text { Modulu } \\
\text { s } \\
\text { (MPa) }\end{array}$} \\
\hline & & Length & Width & $\begin{array}{c}\text { Thickne } \\
\text { ss }\end{array}$ & & & \\
\hline 1 & EPG0 & 250 & 15 & 1 & 128 & 0.028 & 8757 \\
\hline 2 & EPG1 & 250 & 15 & 1 & 206 & 0.029 & 11932 \\
\hline
\end{tabular}




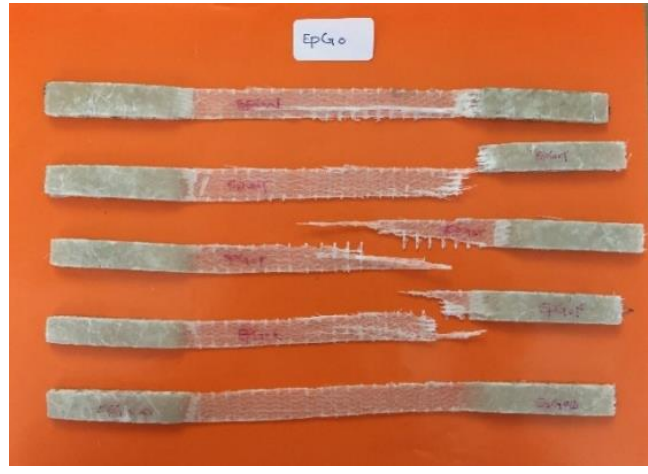

Figure 3 EPG0 samples after tensile testing

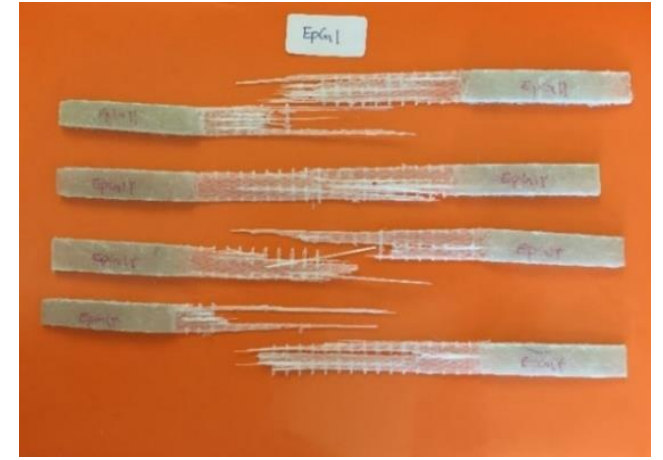

Figure 4 EPG1 samples after tensile testing

\section{NUMERICAL STUDY}

In this section, the impacts of using EPG1 and EPG0 composites on the strengthening of a reinforced concrete beams are investigated. The results are compared with a capacity of a beam without strengthening as a control beam (named as B1). A simply supported reinforced concrete beam strengthened with EPG0 composite, a simply supported reinforced concrete beam strengthened with EPG1 composite, and a simply supported reinforced concrete beam without strengthening (control sample) subjected to two-point loads were modeled and analyzed using finite element software to study the effects of the strengthening. According to the existing symmetry, the beams were modeled as half models, and the symmetry boundary conditions were considered.

The properties of the concrete and steel materials used in numerical modeling are detailed in Table 4 also Figure 9 displays the dimensions and properties of the modeled reinforced concrete beam.

Table 5 displays the mechanical properties of the composite used to reinforce the flexural strength of concrete beams. Also, Table 6 presents the properties of the numerical models.

\subsection{Modeling}

Materials used in the modeling include bars, concrete, and GFRP composite. For modeling the bars, the bilinear complete elasto-plastic is used. The kinematic hardening was used to define steel plasticity.

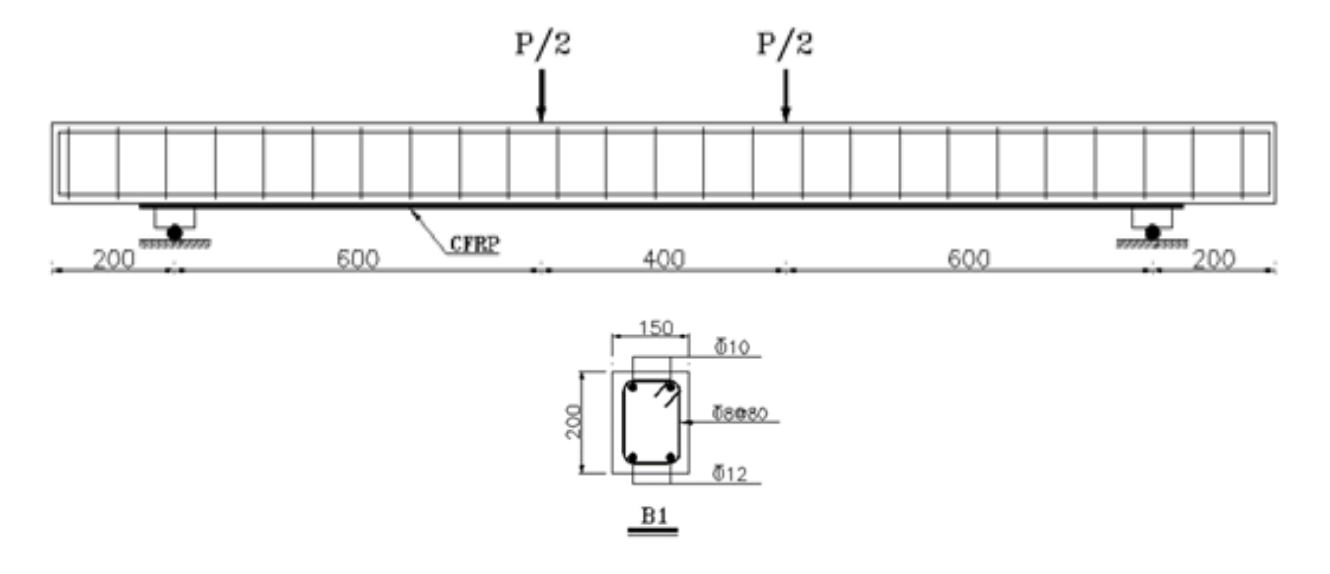

Figure 5 Geometric dimensions and arrangement of longitudinal and transverse bars in concrete beams [12] 
There are different behavioral models for concrete in numerical modeling. In this paper, the continuum, plasticity-based, damage model was used. For modeling of concrete elements, the elements are used by eight nodes having three degrees of freedom at each node.

Moreover, the uniaxial polymer fibers exhibit nonlinear behavior in the in-plane shear strain-stress relationship. The nonlinear behavior of GFRP was modeled via Hashin's failure model $[11,10]$.

Table 4. Mechanical properties of steel and concrete [13]

\begin{tabular}{|c|c|c|c|c|c|}
\hline Material & $\begin{array}{c}\text { Density } \\
\left(\mathbf{K g} / \mathbf{m}^{\mathbf{3}}\right.\end{array}$ & $\begin{array}{c}\text { Modulus of elasticity } \\
(\mathbf{M P a})\end{array}$ & $\begin{array}{c}\text { Yield strength } \\
(\mathbf{M P a})\end{array}$ & $\begin{array}{c}\text { Ultimate } \\
\text { strength (MPa) }\end{array}$ & $\begin{array}{c}\text { Poisson's } \\
\text { ratio }\end{array}$ \\
\hline steel & 7800 & 210000 & 490 & 575 & $\mathbf{0 . 3}$ \\
\hline concrete & 2000 & 23593 & - & 25 & $\mathbf{0 . 2}$ \\
\hline
\end{tabular}

Table 5. Mechanical properties of the composites

\begin{tabular}{|c|c|c|c|}
\hline composite code & $\begin{array}{c}\text { Modulus of elasticity } \\
\text { (MPa) }\end{array}$ & $\begin{array}{c}\text { Ultimate strength } \\
\text { (MPa) }\end{array}$ & Poisson's ratio \\
\hline EPG0 & 8757 & 128 & $\mathbf{0 . 3}$ \\
\hline EPG1 & 11932 & 206 & $\mathbf{0 . 3}$ \\
\hline
\end{tabular}

\subsection{Verification}

In this section, it is tried to validate the modeled beam based on the previous studies. The beam used in this research is similar to the beam used by Rahimi et al. [12]. Therefore, the results of the experimental studies of Rahimi et al. are used to validate the results of the present study. Figure 10 shows the modeling of the beam, and figure 11 presents the forcedisplacement curves of the modeled beam experimental beam. It can be seen from figure 11 that the results of the numerical modeling and the experiment are in good agreement with each other, and numerical beam modeling can be used to achieve the purpose of this research.

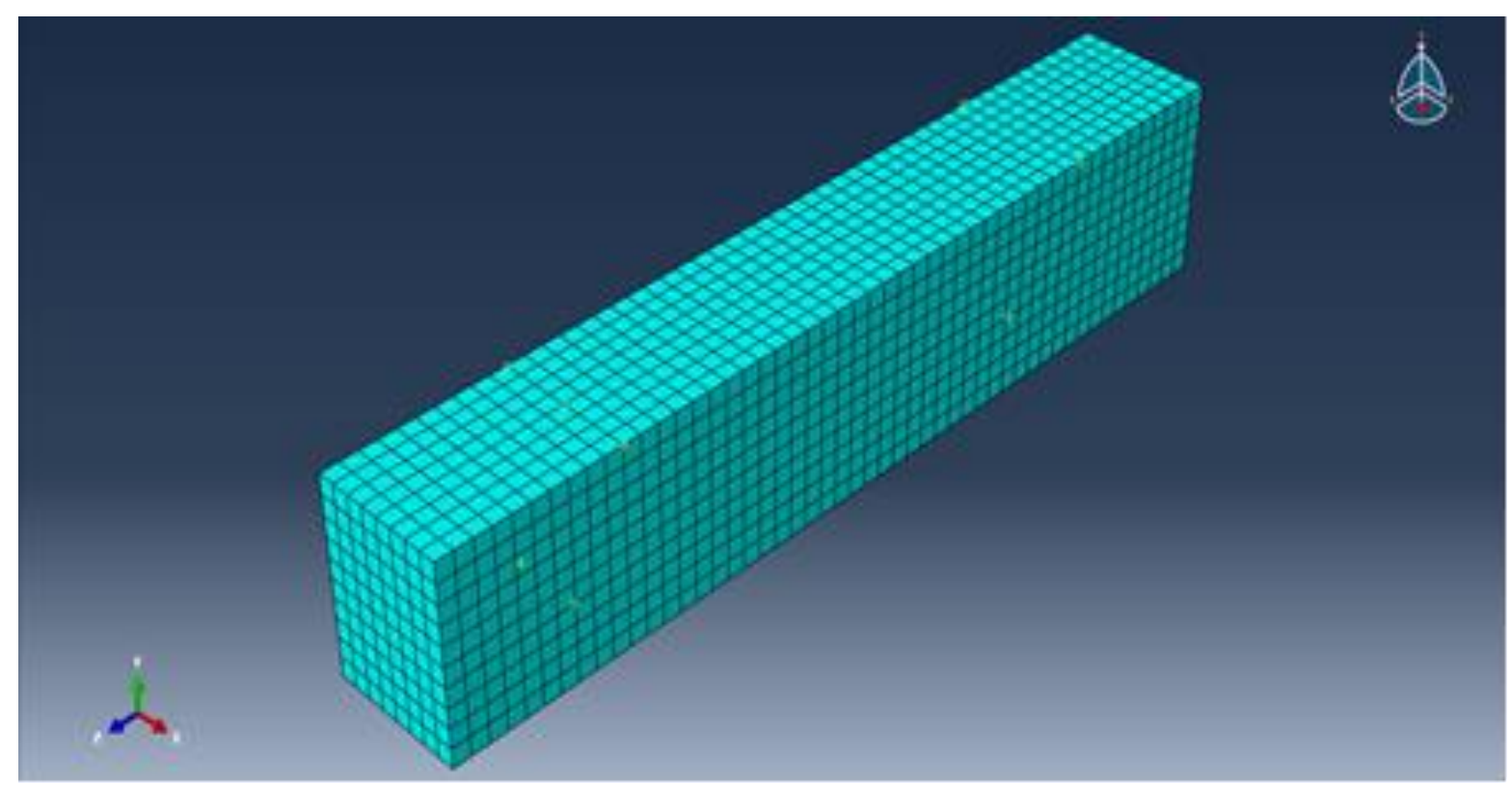

Figure 6 The meshing of the concrete beam 


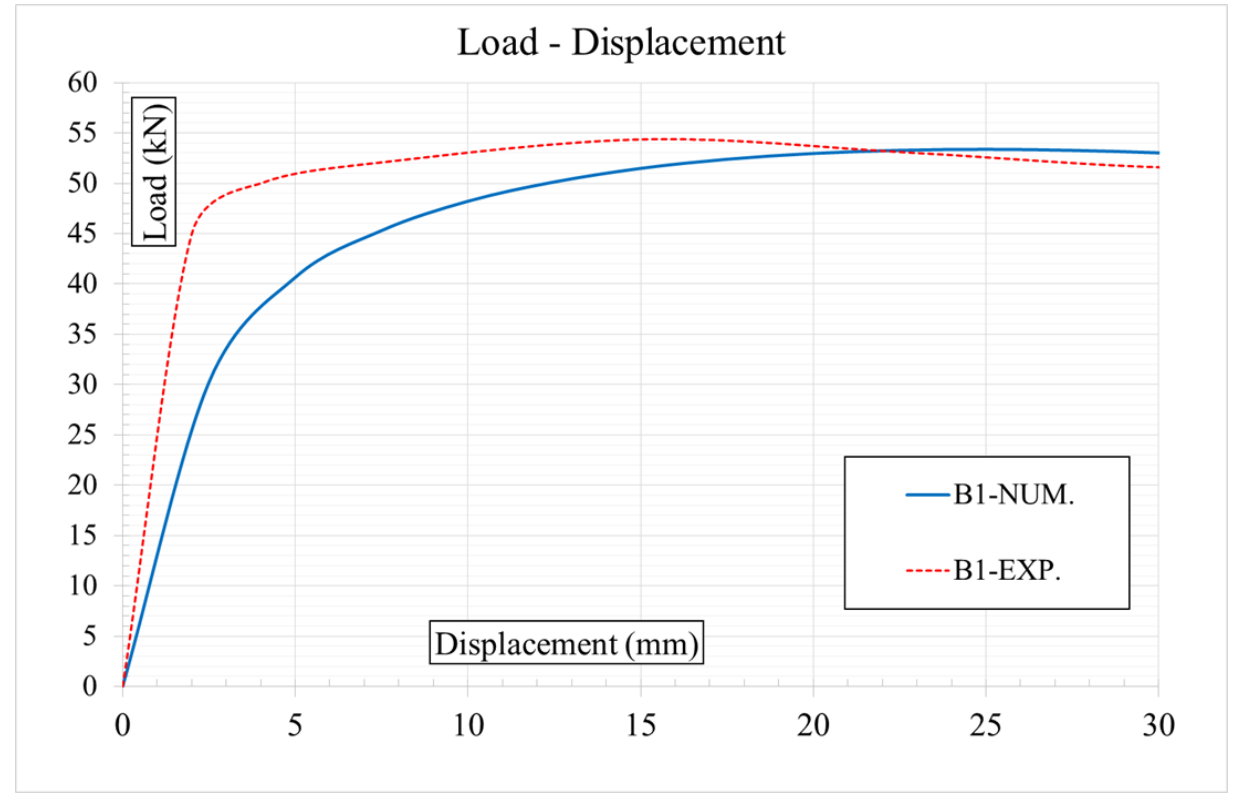

Figure 7 Force-displacement curves used for the verification.

\subsection{Results}

The impact of adding 1\% of 3-aminopropyltriethoxysilane surface modifier to GFRP glass composite on the behavior of concrete beam was presented in this section. Figure 12 illustrates the force-displacement curves in the control beam (B1), strengthened beam with GFRP composite without a surface modifier (EPG0), and strengthened beams with GFRP composite and $1 \%$ surface modifier (EPG1). The obtained results indicate that the unmodified GFRP composite increases the ultimate capacity of the beam from $53.37 \mathrm{kN}$ to $61.23 \mathrm{kN}$ (by $15 \%)$. In comparison, the modified GFRP composites increase the ultimate capacity of the beam from $53.37 \mathrm{kN}$ to $68.1 \mathrm{kN}$ (by $28 \%$ ).

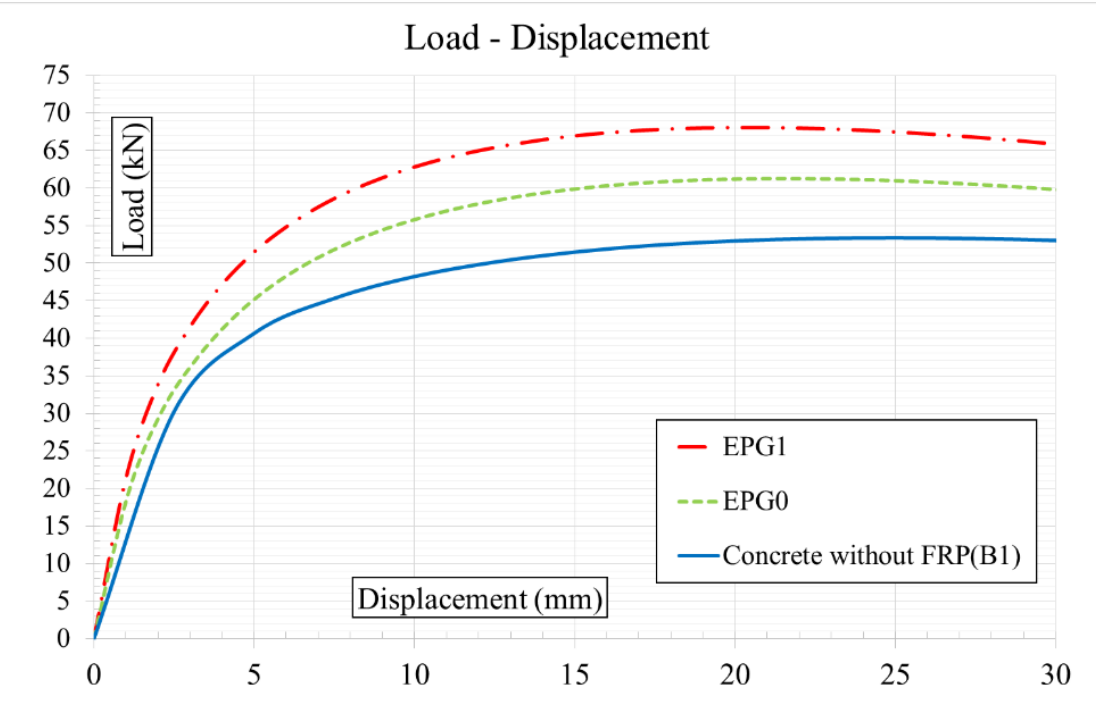

Figure 8 Force-displacement diagram of the B1 beam and the beam reinforced with EPG1 and EPG0 
Investigation on Strengthening of Reinforced Concrete Beams with GFRP Composites Modified by Silane Agent

Table 7 Comparison of the ultimate bearing capacity in a reinforced and unreinforced beam

\begin{tabular}{|c|c|c|}
\hline Beam & $\begin{array}{c}\text { Ultimate capacity of } \\
\text { beam }(\mathbf{k N})\end{array}$ & $\begin{array}{c}\text { increase in } \\
\text { capacity (\%) }\end{array}$ \\
\hline B1 & 53.372 & - \\
\hline EPG0 & 61.23 & $\mathbf{1 5}$ \\
\hline EPG1 & 68.1 & $\mathbf{2 8}$ \\
\hline
\end{tabular}

Figures 13-17 present the stress distribution contour plots in the beam without strengthening (B1), and strengthened beam with GFRP composites without modifiers (EPG0), and a strengthened beam with GFRP composites with $1 \%$ modifiers (EPG1).

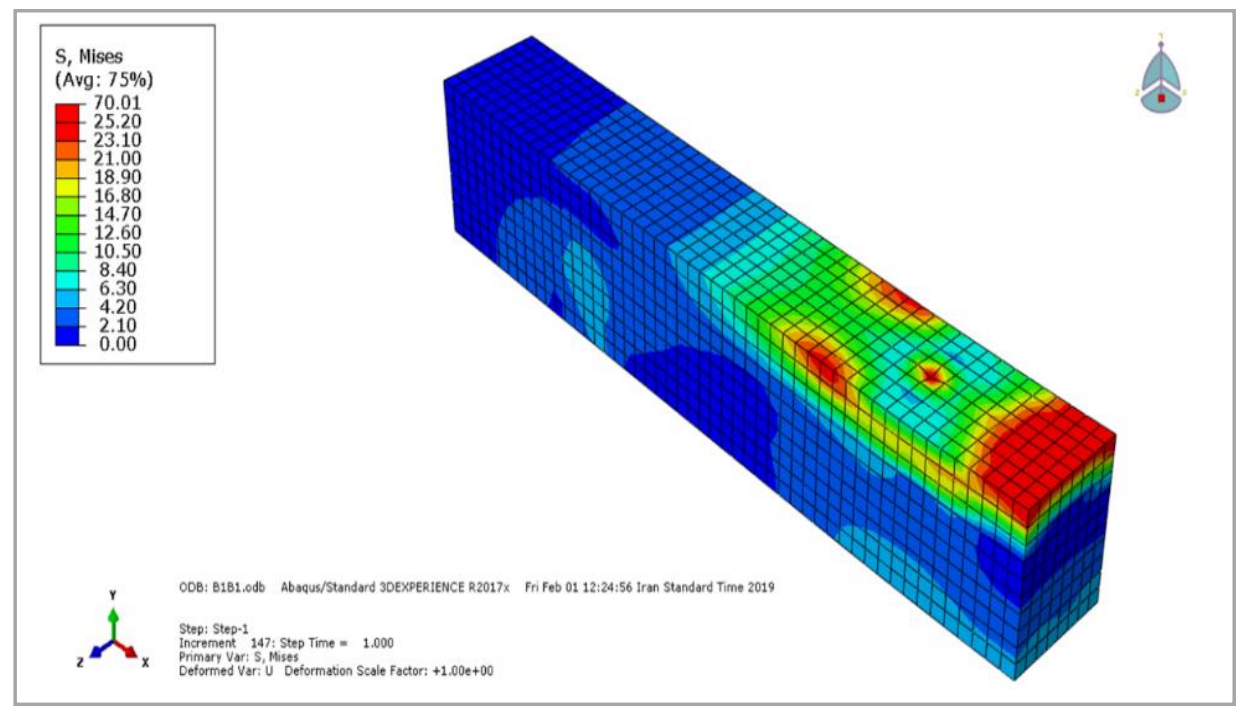

Figure 9 Stress distribution contour plot in the reinforced concrete beam without strengthening (B1)

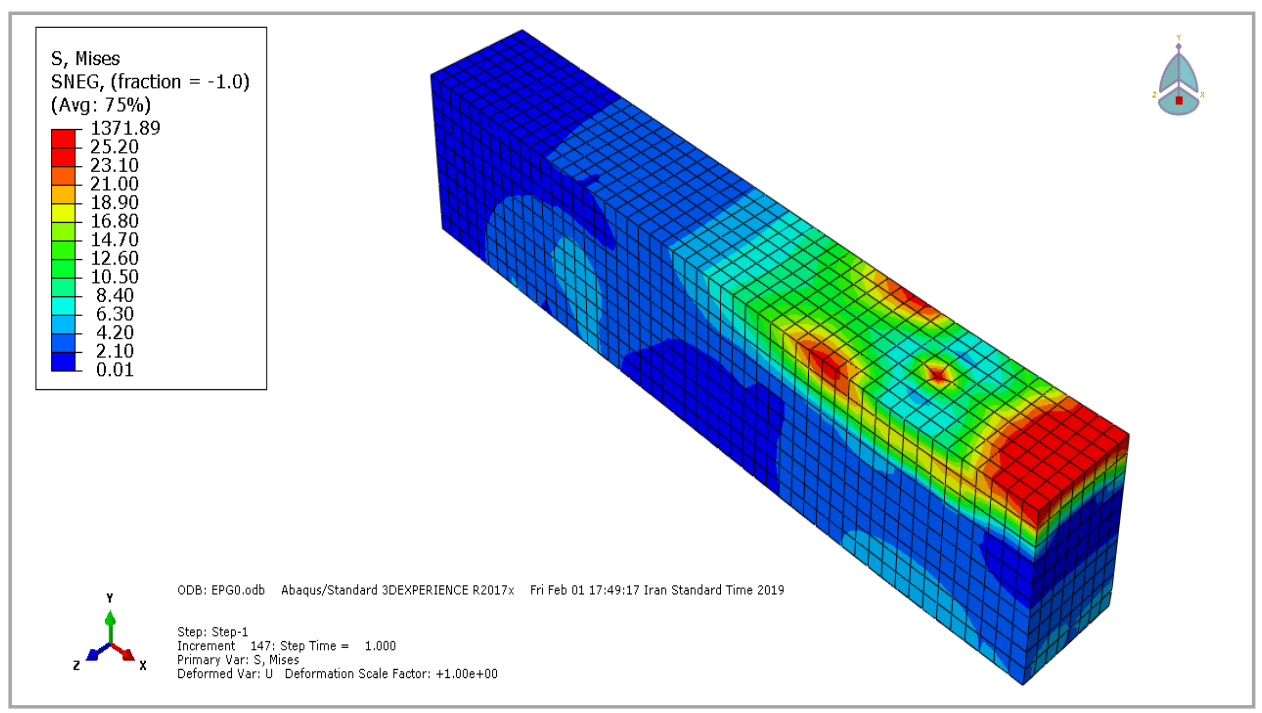

Figure 10 Stress distribution contour plot in the concrete beam strengthened with EPG0 composite 
Sara Rafiee, Sadegh Dardaei and Hamed Bagheri

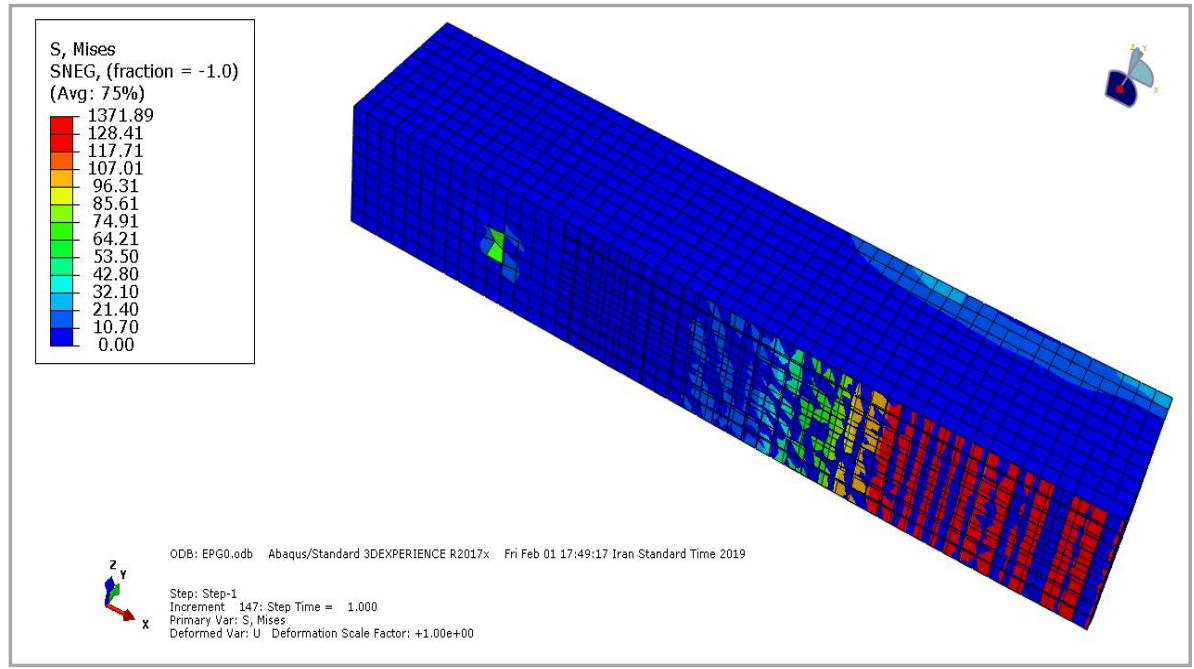

Figure 11 Composite stress distribution contour plot in the concrete beam strengthened with EPG0 composite

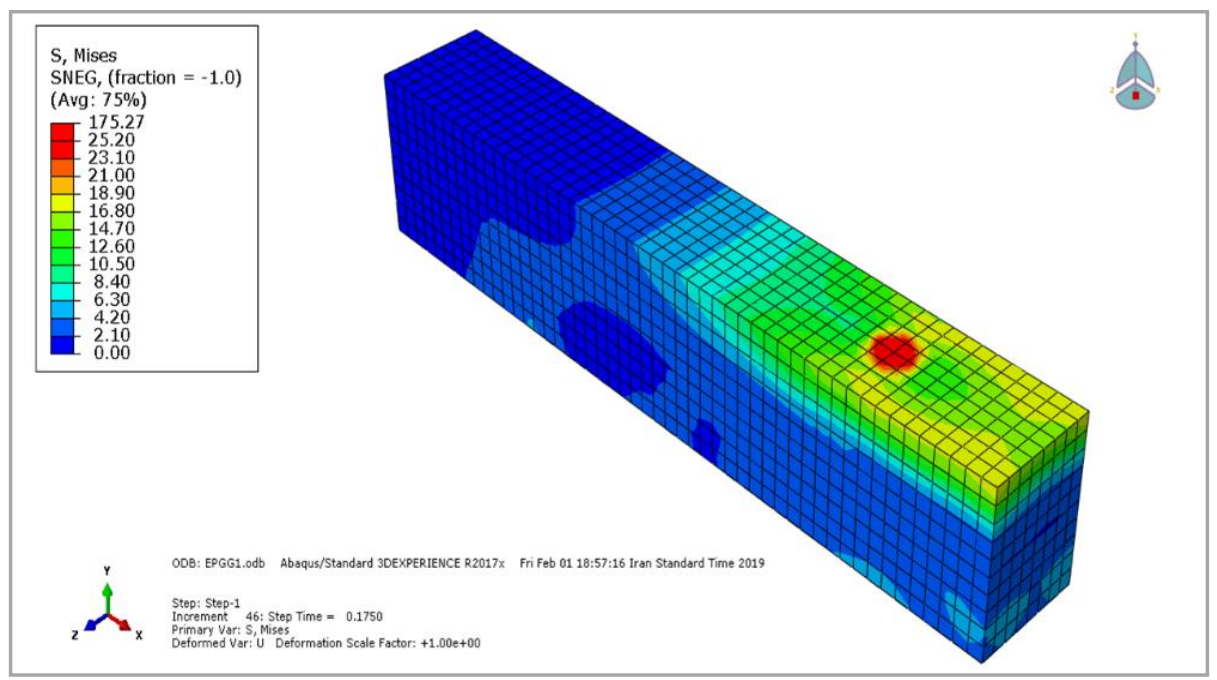

Figure 12 Stress distribution contour plot in the concrete beam strengthened with EPG1 composite

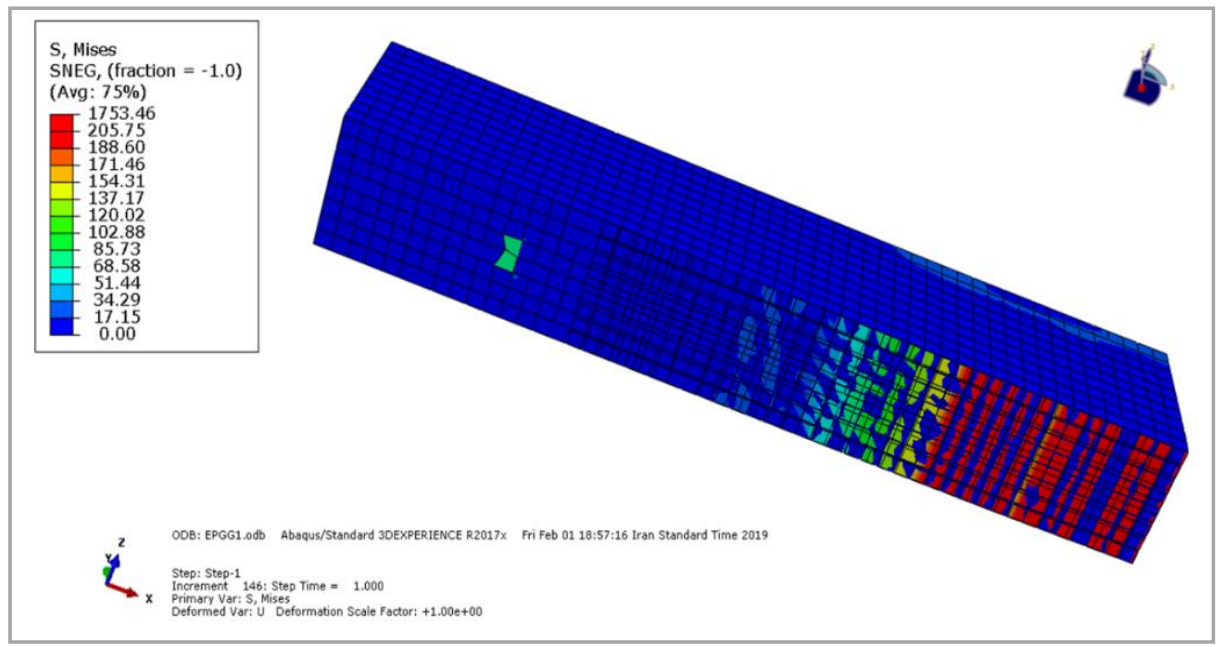

Figure 13 Composite stress distribution contour plot in the concrete beam strengthened with EPG1 composite 
Investigation on Strengthening of Reinforced Concrete Beams with GFRP Composites Modified by Silane Agent

\section{CONCLUSION}

In this paper, the effects of adding a surface modifier to the GFRP composite and its subsequent effects on the capacity of a reinforced concrete beam using the numerical method were investigated. Based on the studies conducted in this research, it can be concluded:

1. In the experimental study adding the silane agent caused a $60 \%$ and $36 \%$ increase in tensile strength and tensile modulus of GFRP composite samples.

2. Strengthening the concrete beams by GFRP composite without surface modifier increases the capacity of the concrete beam by $15 \%$.

3. Strengthening the concrete beams by GFRP composite and with the appropriate percentage of surface modifier increases the capacity of the beam by $28 \%$.

Finally, using other modifiers to improve the adhesion of fibers to the resin and increasing the capacity of concrete beams are recommended for further studies.

\section{REFERENCES}

[1] Rahaei, A, Zomorrodian, A. (2007) "Evaluation of performance of reinforced concrete beams reinforced with FRP sheets under static and cyclic loads" Modares Technical and Engineering Periodical (No. 25), Tarbiat Modares University, Tehran, Iran (in persian).

[2] Imani, H. et al., (2009), "Nonlinear Finite Elment Analysis of reicnforced concrete beam retrofitted by FRP”, 8th International Congress on Civil Eng., Shiraz, Iran (in persian).

[3] Rathish Rajan, Egidija Rainosalo, Selvin P Thomas, Sunil Kumar Ramamoorthy (2018) "Modification of Epoxy Resin by Silane-Coupling Agent to Improve Tensile Properties of Viscose Fabric Composites", Polymer Bulletin.

[4] Memar, M., Dehghanian, A., Haddadi, S.A, (2016) "Investigation of the effect of adding silane tri-methoxy (vinyl) silane to vinyl ester resin to improve the adhesion of fibers to the core in sandwich composites", 18 Marine Industries Conference, Kish, Iran (in persian).

[5] Kejing Yu, Haijian Cao, Kun Qian, Hongshun Li, Juanjuan Wang (2013) "Effect of Two-Step Surface Treatment on the Mechanical Properties of Hollow Integrated Core Sandwich Composites with GF/CF Hybrid Face Sheets", Journal of Engineered Fibers and Fabrics, Wuxi, jiangsu China.

[6] Dardaei, S., Bagheri, H., Esmaeili, N., (2020) "Using Polyether Ether Ketone Particles in GFRP Composites for Strengthening of Reinforced Concrete Beams" International Journal of Civil Engineering and Technology (IJCIET), Volume 11, Issue 1, pp. 190-198.

[7] Rabiee, A. (2016) "Cilani Modifying Factors, Introduction and Application", Polymerization quarterly, Volume: 6, Issue: 3 , (in persian).

[8] ASTM D638-10 (1997) "Standard Test Method for Tensile Properties of Plastics".

[9] ASTM D3039 (2002) "Standard Test Method for Tensile Properties of Polymer Matrix Composite Materials",

[10] Lubliner, J., Oliver J., Oller S., Onate E., (1989) "Plastic-damage model for concrete", International Journal of Solids and Structures, 25, (3), pp. 299-326.

[11] Rahimi, H., Hutchinson A., (2001) "Concrete beams strengthened with externally bonded FRP plates", Journal of Composite Construction, 5, (1), pp. 44-56. 